\title{
Editorial
}

\section{Displaced Intraarticular Calcaneus fractures: To Fix or not to Fix? That is the ques- tion}

Displaced intraarticular calcaneus fractures (DIACFs) are a source of devastating disability to the patient, a potential hornet's nest for the average orthopedic surgeon and a potential economic burden on the society. Till today, no single treatment approach is universally applicable to all patients and all fracture types. ${ }^{1}$ The goal of treatment has been anatomical reduction, stable fixation, and early functional rehabilitation. However, it is also well understood that surgeon factors, such as faulty surgical technique, improper timing, inexperience, or patient factors like preexisting comorbidities, such as peripheral vascular disease, diabetes, and smoking adversely affect wound healing and can lead to terrible soft tissue complications, increased morbidity, and delayed healing. ${ }^{2,3}$ It has been well established that patients with DIACFs have poorer functional results than those for other orthopedic conditions. ${ }^{4}$

More than a decade ago, Buckley et $\mathrm{al}^{2}$ set the cat among the pigeons when they reported that, in their randomized controlled trial in 2002, the functional results of operative or nonoperative treatment of DIACFs were similar. However, looking beyond the headline, it was pointed out by the authors that women, younger patients $(<29$ years old), those not receiving workers' compensation, those with a lighter workload and with anatomical reduction intraoperatively (a step-off $<2 \mathrm{~mm}$ ) had significantly better functional scores following surgery.

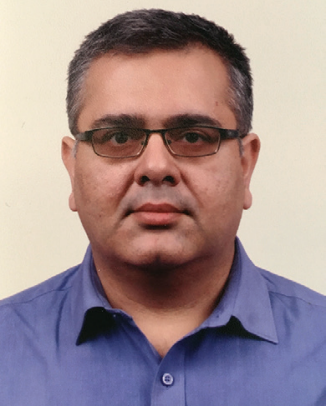

Sharad Prabhakar

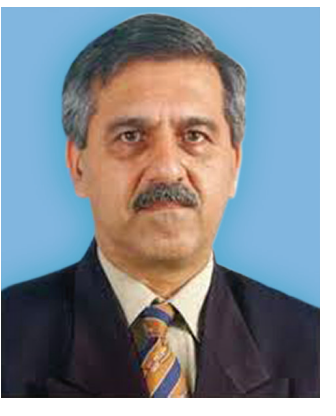

Mandeep S Dhillon

More recently, Bruce and Sutherland ${ }^{5}$ in their Cochrane review published in 2013 stated that there was insufficient high-quality evidence to establish whether surgical or nonoperative treatment is better for DIACFs. A total of four trials were included with data published across multiple $(n=20)$ publications. ${ }^{2,6-8}$ The trials in the review were published between 1993 and 2002. The largest trial ${ }^{2}$ had recruited 426 participants between 1991 and 1997. The authors stated that the trial by Buckley et $\mathrm{al}^{2}$ formed a large part of the review. The authors reiterated that, once the workers' compensation cases were excluded, surgical outcomes improved in subgroup analysis. They also suggested that, as subgroup analysis were conducted and presented across multiple publications, it resulted in different sample sizes and different time to follow-up with reanalysis of primary outcomes. Thus, as the evidence in this review was largely driven by Buckley's study, the Cochrane review could not find any difference between operative vs nonoperative intervention for DIACFs. The authors also mentioned that data from the then just concluded multicentric UK Heel fracture trial were not included in the review and its results were eagerly anticipated.

The UK Heel Fracture Trial by Griffin et al $^{9}$ was published in July, 2014, in the BMJ as a pragmatic, multicentric, randomized controlled trial with the conclusion that operative treatment compared with nonoperative care showed no symptomatic or functional advantage after 2 years in patients with DIACFs, and the risk of complications was higher after surgery. Thus, open reduction and internal fixation was not recommended for calcaneus fractures.

The trial's sensational claim lead to a furor of responses and the trial was severely criticized by several researchers for obviously faulty methodology. It was pointed out that selection bias was a key factor. Only 502 of 2,006 patients with calcaneal fractures were found eligible for randomization in this study. This was because all fractures with a severe valgus or varus deformity of the heel, requiring operative intervention, had actually been excluded from the study. Furthermore, only 151 of the remaining 502 patients agreed to take part in the study, representing a paltry $7.5 \%$ of all of the calcaneal fractures presenting to hospitals. A total of 27 surgeons in 22 different hospitals operated on average of only two fractures for this study.

In his response, Buckley in $2015^{10}$ stated that younger patients with simple DIACFs and without workers' compensation definitely do well surgically. He stressed that DIACFs need to be managed by specialty foot and ankle surgeons and that nonoperative treatment of DIACFs will lead to more subtalar fusions.

In conclusion, RCTs and inconclusive meta-analyses prove that no single treatment approach can be 
applied as a generalization to all calcaneal fractures. DIACFs are injuries which need foot and ankle specialist assessment and intervention with a patient-centric, fracture-tailored approach. Operative intervention with defined indications, anatomical reduction, and meticulous soft tissue dissection in the well-selected patients yield favorable outcomes. Minimally invasive or limited open approaches, using either image intensifier or arthroscopy assisted, have shown promising results. As Buckley has stated, future trends point toward limited open reductions with smaller incisions, thus, ensuring a lower risk of complications while obtaining and ensuring anatomical fracture reduction.

\section{REFERENCES}

1. Sharr PJ, Mangupli MM, Winson IG, Buckley RE. Current management options for displaced intra-articular calcaneal fractures: Non-operative, ORIF, minimally invasive reduction and fixation of primary ORIF and subtalar arthrodesis. A contemporary review. Foot Ankle Surg 2016 Mar;22(1):1-8.

2. Buckley R, Tough S, McCormack R, Pate G, Leighton S, Petrie D, Galpin R. Operative compared with nonoperative treatment of displaced intra-articular calcaneal fractures: a prospective, randomized, controlled multicenter trial. J Bone Joint Surg Am 2002 Oct;84-A(10):1733-1744.

3. Howard JL, Buckley R, McCormack R, Pate G, Leighton R, Petrie D, Galpin R. Complications following management of displaced intra-articular calcaneal fractures: a prospective randomized trial comparing open reduction internal fixation with nonoperative management. J Ortho Trauma 2003 Apr;17(4):241-249.

4. van Tetering EA, Buckley RE. Functional outcome (SF-36) of patients with displaced calcaneal fractures compared with SF-36 normative data. Foot Ankle Int 2004 Oct;25(10):733-738.

5. Bruce J, Sutherland A. Surgical versus conservative interventions for displaced intra-articular calcaneal fractures. Cochrane Database Syst Rev 2013 Jan 31;1:CD008628.

6. Chrintz H, Sonne-Holm S. Clinical results after conservative versus operative treatment of dislocated intraarticular fractures of calcaneus. Acta Orthopaedica Scandinavica - Supplementum 1993;251:64.

7. Ibrahim T, Rowsell M, Rennie W, Brown AR, Taylor GJ, Gregg PJ. Displaced intra-articular calcaneal fractures: 15 year follow-up of a randomised controlled trial of conservative versus operative treatment. Injury 2007 Jul;38(7):848-855.

8. Thordarson DB, Krieger L. 1996 ORIF versus non-operative treatment of intraarticular fractures of the calcaneus: A prospective randomised trial [Abstract]. Orthopaedic Transactions, 1996;20(1):23.

9. Griffin D, Parsons N, Shaw E, Kulikov Y, Hutchinson C, Thorogood M, Lamb SE. UK Heel Fracture Trial Investigators. Operative versus non-operative treatment for closed, displaced, intra-articular fractures of the calcaneus: randomised controlled trial. BMJ 2014 Jul 24;349:g4483.

. 10. Buckley R. Commentary, evidence-based orthopaedics. J Bone Joint Surg Am 2015;97:341.

Sharad Prabhakar

Associate Professor

Department of Orthopaedics

Postgraduate Institute of Medical Education and Research

Chandigarh, India

Mandeep S Dhillon

Professor and Head

Department of Orthopaedics

Postgraduate Institute of Medical Education and Research

Chandigarh, India 